\title{
Enhancement of the Wettability and Lubrication of Shale Rock via Nanoemulsions
}

\author{
Quan Xu, ${ }^{1}$ Qingqiao Li, ${ }^{1}$ Xu Wu, ${ }^{1}$ Bofan Li, ${ }^{1}$ Erdong Yao, ${ }^{1}$ Yuan Li, ${ }^{1}$ \\ Fujian Zhou, ${ }^{1}$ Yan Luo, ${ }^{2}$ and Wei Cai ${ }^{1}$ \\ ${ }^{1}$ State Key Laboratory of Heavy Oil Processing, China University of Petroleum (Beijing), Beijing 102249, China \\ ${ }^{2}$ Department of Chemical Engineering, West Virginia University, Morgantown, WV 26506, USA
}

Correspondence should be addressed to Quan Xu; xuquan@cup.edu.cn

Received 2 August 2017; Accepted 2 October 2017; Published 31 October 2017

Academic Editor: Chaoqun Zhang

Copyright (c) 2017 Quan Xu et al. This is an open access article distributed under the Creative Commons Attribution License, which permits unrestricted use, distribution, and reproduction in any medium, provided the original work is properly cited.

\begin{abstract}
Nanoemulsions have been widely used as additives for drilling fluids in recent years. With the development of nanotechnology, multifunctional nanomaterials have been added to nanoemulsions. The improvement of wettability of the surfaces, alteration of oil-wet on shale rock surfaces, and environmentally friendly conditions are considered as the future development directions of nanoemulsions. In this work, a novel nanoemulsion was prepared by using hydrocarbon-based polyoxyethylene ether, oil (hydrocarbon), distilled water, and formation crude oil as the main raw materials. The shale rocks before and after immersion with as-prepared nanoemulsion were characterized by contact angle measurement, atomic force microscope (AFM), and Fourier transform infrared spectroscopy (FTIR). It is clearly observed that the nanoemulsion greatly improved the wettability of the sandstone and rock surface by forming a layer of active agent film on the surface of the rock. The as-prepared nanoemulsion had good ability to curb the anticollapse and lubricate and protect the oil and gas layer.
\end{abstract}

\section{Introduction}

Nanoemulsion is a transparent/translucent $(50-200 \mathrm{~nm})$ or milky white emulsion (about $500 \mathrm{~nm}$ ). It also has developed as small emulsion, ultrafine emulsion, latex liquid, unstable emulsion, and submicron emulsion. The introduction of nanomaterials in the drilling completion fluid can solve urgent issues, such as stability performance and environmentally friendly composites [1]. When the nanoemulsion was applied to drilling, solid particles and the filtrate from the drilling and completion were prevented from the deep formation to avoid permanent blockage in the oil and gas flow channel [2]. This played very important role in the protection of oil and gas layer. The current pilot exploration research showed that in the field of oil and drilling fluid nanoemulsion had a very strong attraction.

In this work, rock with a porosity of $11.6 \%$ and a permeability of $0.0001-1 \mathrm{mD}$ was derived from Jimusaer dense oil reservoir [3-7]. The average density and viscosity of the crude oil were, respectively, $0.888 \mathrm{~g} / \mathrm{cm}^{3}$ and $73.45 \mathrm{mPa} \cdot \mathrm{s}$.
The freezing point was $24.84^{\circ} \mathrm{C}$, which belonged to high temperature and high freezing point. The basic information about Jimusaer dense oil reservoir was listed in Table 1 .

In this work, the surface of the rock in Jimusaer oil field was modified by nanoemulsion due to the improved wettability of the rock surface and formed active agent film. This provided a new idea for the optimization of sandstone drilling fluid and the improvement of the stability of sandstone gas shaft [8-10].

\section{Experiment}

2.1. Materials. Alkyl polyoxyethylene ether, oil (hydrocarbons), distilled water, stratified crude oil, and rock samples were obtained from Changji Oilfield.

2.2. Experiment. The experiments were processed as follows:

(1) Diluted crude oil: a diluted crude oil with a viscosity of $10.83 \mathrm{mPa} \cdot \mathrm{s}$ was obtained by mixing crude oil with kerosene at a ratio of $1: 1.25$. 
TABLE 1: The basic information of the Jimusaer dense oil reservoir.

\begin{tabular}{lcc}
\hline $\begin{array}{l}\text { Block } \\
\text { Oil layer }\end{array}$ & Changji oilfield \\
Thickness of the reservoir $(\mathrm{m})$ & Lauza ditch group on the desert & Luca ditch group under the desert \\
Lithology & 16 (thin interbed) & 20 (thin interbed) \\
Natural cracks & Cloudy siltstone \\
Porosity $(\%)$ & Not developed & Not developed \\
Permeability $(\mathrm{mD})$ & 11.0 & 11.6 \\
Oil saturation $(\%)$ & 0.012 & 0.010 \\
Formation pressure coefficient & 78.7 & 80.2 \\
Reservoir temperature $\left({ }^{\circ} \mathrm{C}\right)$ & & $1.273 \sim 1.32$ \\
Crude oil viscosity $\left(\mathrm{mPa} \cdot \mathrm{s}, 50^{\circ} \mathrm{C}\right)$ & 86.6 & 93 \\
Stratified crude oil viscosity $(\mathrm{mPa} \cdot \mathrm{s})$ & 64.3 & 204.6 \\
Ground crude oil density $\left(\mathrm{g} / \mathrm{cm}^{3}\right)$ & 10.58 & 21.5 (calculation) \\
\hline
\end{tabular}

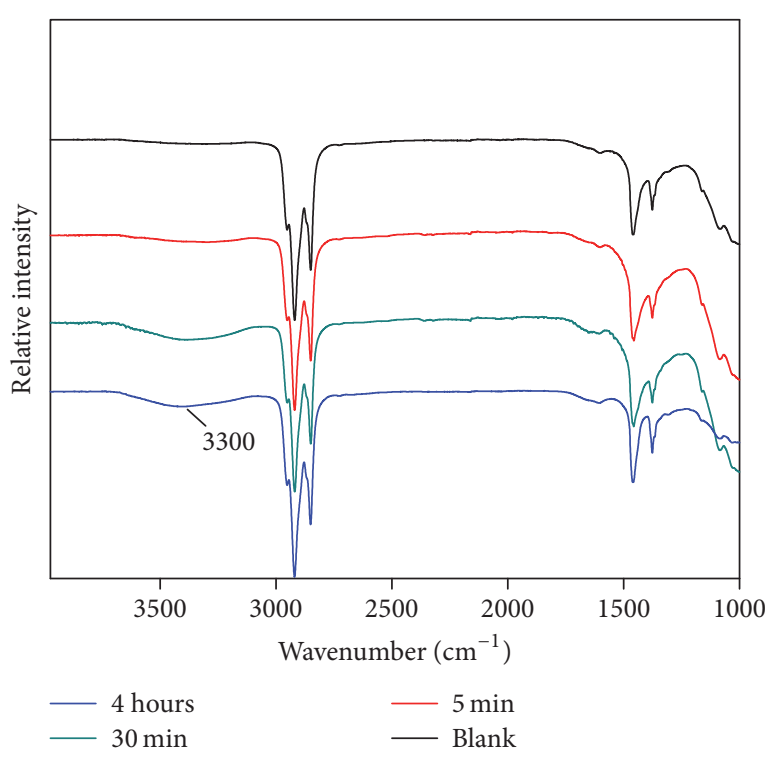

(a)

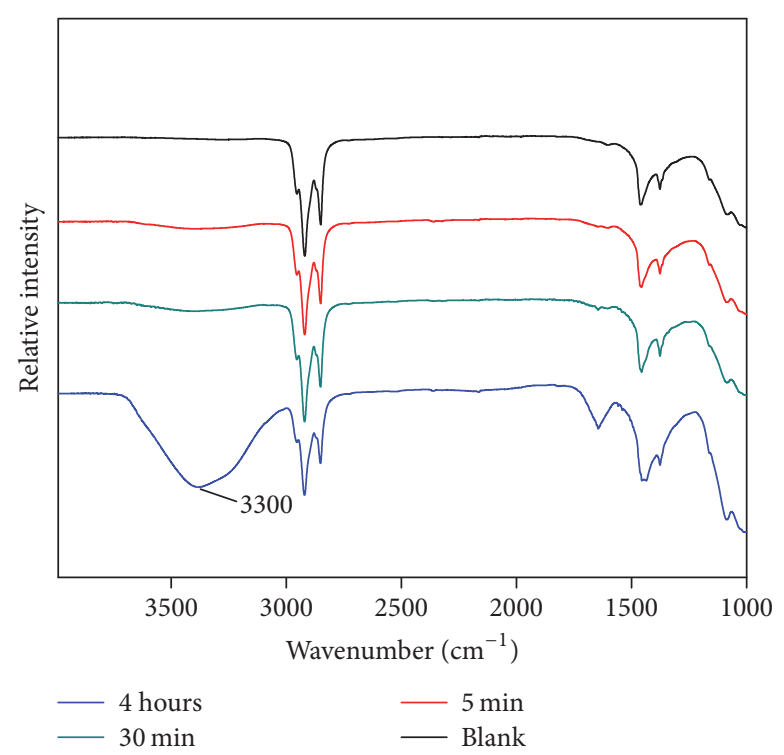

(b)

FIGURE 1: FTIR spectra of soaked sandstone samples: (a) sandstone soaked under $\mathrm{NaCl}$ solution for different immersion times and (b) sandstone soaked with nanoemulsions at different immersion time.

(2) Nanoemulsion mother liquor configuration: a certain amount of the surfactant (hydrocarbyl polyoxyethylene ether), alcohol, and oil (hydrocarbons) were mixed. Subsequently, distilled water was added to generate microemulsion mother liquor.

(3) Nanoemulsion configuration: nanoemulsion was obtained by mixing microemulsion mother liquor and $2 \% \mathrm{KCl}$ solution at the ratio of $0.1: 100$.

(4) Rock soaking: the core was cut into $1 \mathrm{~cm}$ thick and $2.5 \mathrm{~cm}$ diameter with 1000 mesh sandpaper polished smooth; then, it was soaked with diluted oil for 10 days.

(5) Remove the rock and immerse it into nanoemulsion.
(6) The soaked rock was analyzed by FTIR, atomic force microscopy (AFM) and contact angle.

\section{Results and Discussion}

3.1. FTIR. Rocks soaked in $\mathrm{NaCl}$ solution and nanoemulsions for different immersion time (blank sample, $5 \mathrm{~min}, 30 \mathrm{~min}$, and $4 \mathrm{~h}$ ) were characterized by FTIR (Figures $1(\mathrm{a})$ and $1(\mathrm{~b})$ ). It is clearly seen that a strong peak at $3300 \mathrm{~cm}^{-1}$ occurred after nanoemulsion soaking [11-15]. The longer the soaking time, the stronger the relative intensity of the peak. This peak corresponded to a group with strong polarity, indicating that the nanoemulsion can greatly improve the wetting of the sandstone surface [15-18]. 


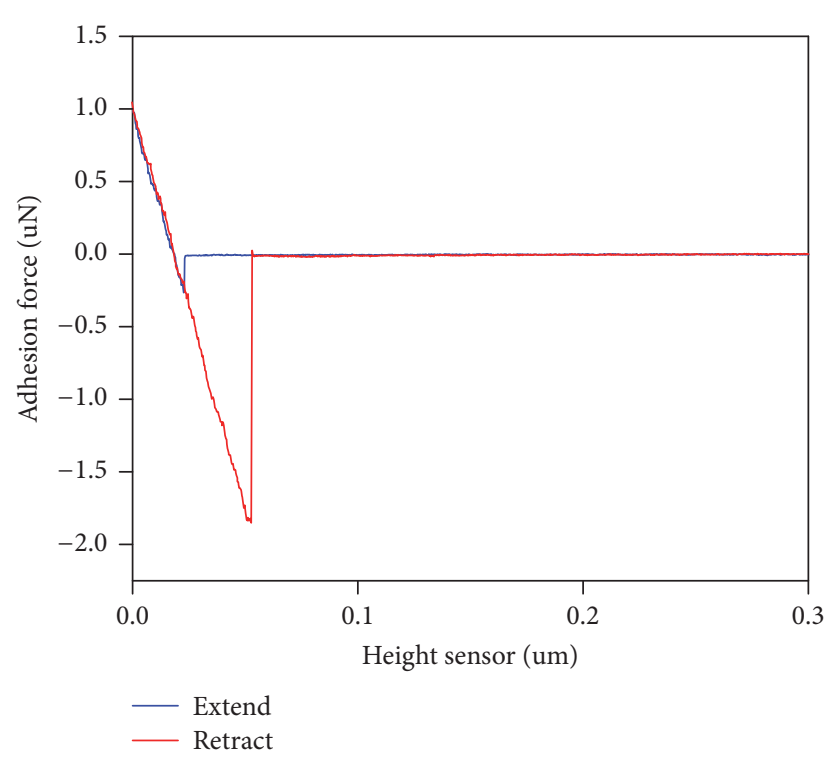

(a)

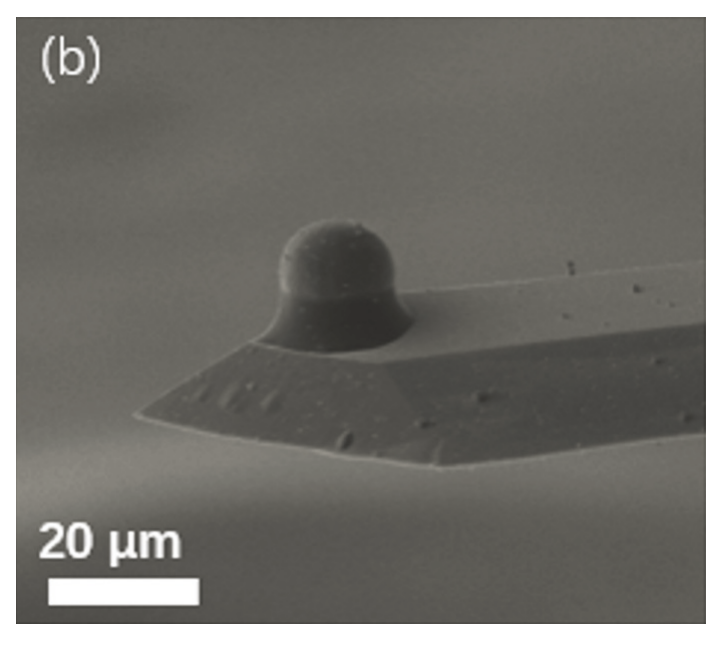

(b)

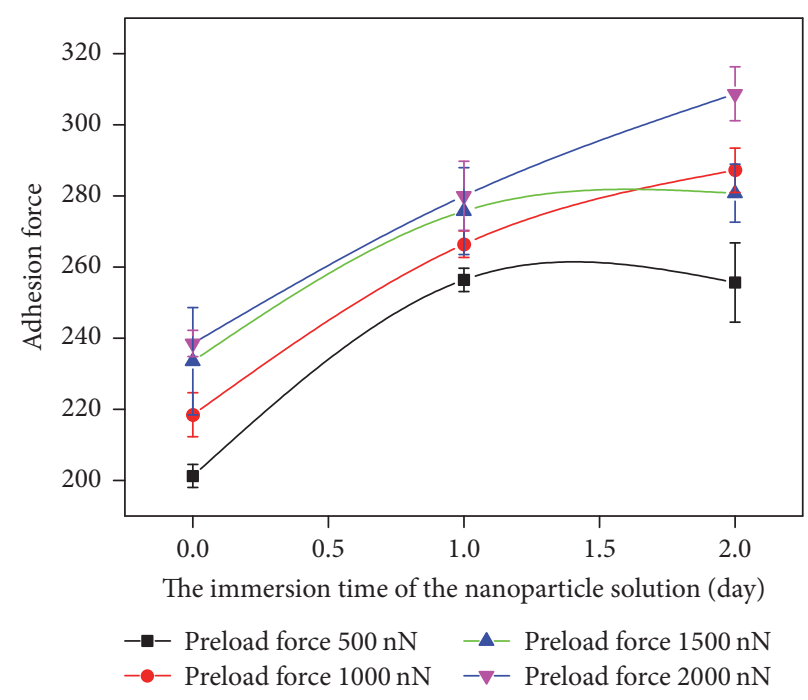

(c)

FIGURE 2: (a) A typical force curve data, (b) a typical AFM tip probe, and (c) adhesion force between rocks and probes under different soaking time with nanoemulsions.

3.2. AFM Adhesion Test. Figure 2 gives the adhesion forces between probes and rock surfaces under different nanoemulsion soaking time. All the tests were performed at a temperature of $23^{\circ} \mathrm{C}$ with humidity $23 \%$. The same positions on the rocks were tested (experimental conditions: ramp size $500 \mathrm{~nm}$, reserved velocity $1000 \mathrm{~nm} / \mathrm{s}$, preload time $0 \mathrm{~s}$, and temperature $19^{\circ} \mathrm{C}$ ) [19]. Figures 2(a) and 2(b) are a typical adhesive force curve and tip probe detected under AFM. It can be seen from Figure 2(a) that the adhesion force between particle and substrate increased with the increase of soaking time. The adhesive force shown in Figure 2(c) also increased as the loading force increased from 500 to $2000 \mathrm{nN}$, indicating that the surfactant in the nanoemulsion was effectively spread on the shale rock surface and formed a layer of active agent film with high stability performance.

3.3. Contact Angle. Wettability refers to the tendency of another fluid to expand or adhere to the solid surface when there is a mixed fluid [20]. It is the interaction between oil and water and reservoir rocks under reservoir conditions. According to the affinity between the reservoir rock surface and water and oil, the reservoir wetting property is divided into water wetting, oil wetting, neutral wetting, and subwetting. Reservoir wettability is the main factor to control the flow and distribution of fluid in reservoirs [21]. Therefore, the study of reservoir wettability is of great significance to the 


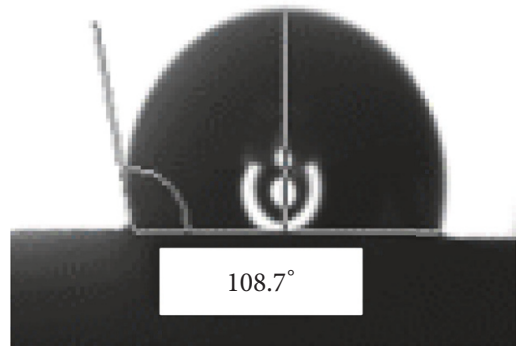

(a)

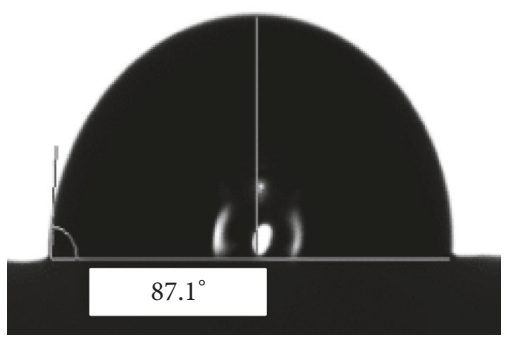

(c)

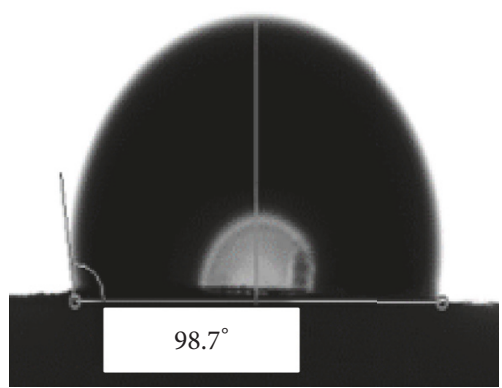

(b)

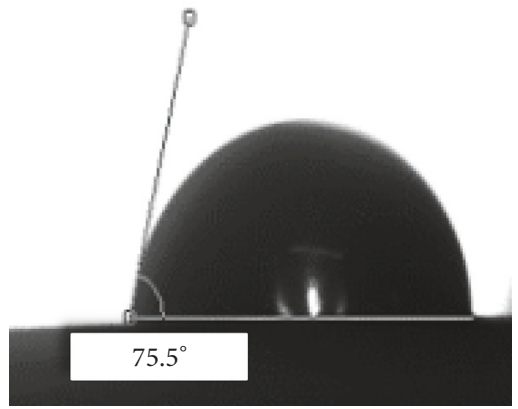

(d)

FIGURE 3: Contact angle of water droplets in air; rocks soaked in the nanoemulsion for various times, (a) 1 day, (b) 3 days, (c) 7 days, and (d) 9 days.

development of oil field and the final recovery rate of crude oil [22].

The contact angle method is mainly used for the determination of wettability of pure fluid and artificial core systems. The wettability of the system is usually defined according to the determination of the angle $\theta$ of the water on the solid surface. Generally, $\theta<75^{\circ}, 105^{\circ}>\theta>75^{\circ}$, and $\theta>105^{\circ}$ are defined as water wetting, neutral wetting, and oil wetting, respectively.

Figures 3(a)-3(d) are the contact angle of the rock sample immersed in the nanoemulsions for different soaking times. It can be clearly seen that the oil was wetted when the rock was soaked in the nanoemulsion for 1 day (Figure 3(a)) but weakly wetted when immersed for 3, 7, and 9 days (Figures $3(b)-3(d)$ ). The graph inferred that the wetting of the rock surface changed with the immersion time.

3.4. The Schematic of the Reaction. Nanoemulsions are usually thermodynamically stable isotropic dispersions of oil, water, surfactants, and cosurfactants spontaneously formed. Figure 4 is the model of nanoemulsion structure [23]. From the microscopic principle analysis, the nanoemulsion is a heterogeneous dispersion, which consists of a continuous aqueous phase and a polymer dispersed in water in a microsphere form. During the emulsion formation process, the water is gradually volatilized or absorbed by the porousness of the surface. Then, the microspheres of the polymer slowly

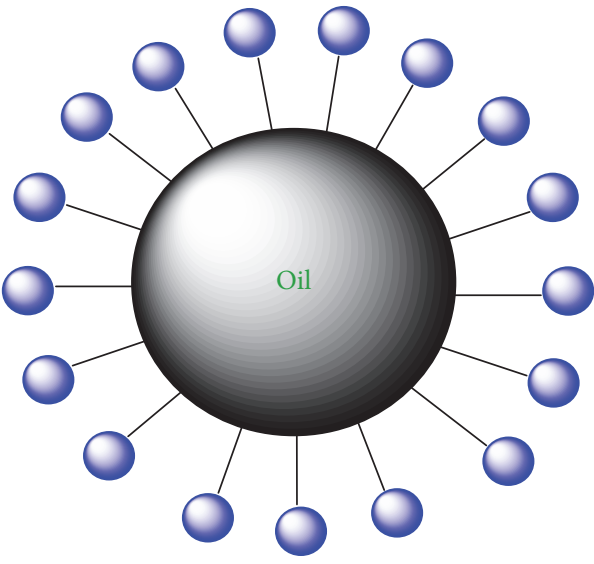

FIGURE 4: Nanoemulsion structure model.

approach and finally contact each other until the polymer particles fuse with each other to form a continuous uniform coating [24].

Figure 5 is the schematic diagram of shale rock soaked in nanoemulsions. It can be seen that when the nanoemulsions are dispensed onto water surface under gravity, it can mix with rock in two ways; one is spreading on the surface and the other is infiltration into rocks. Since the infiltration speed of water is much higher than that of nanoemulsions, 


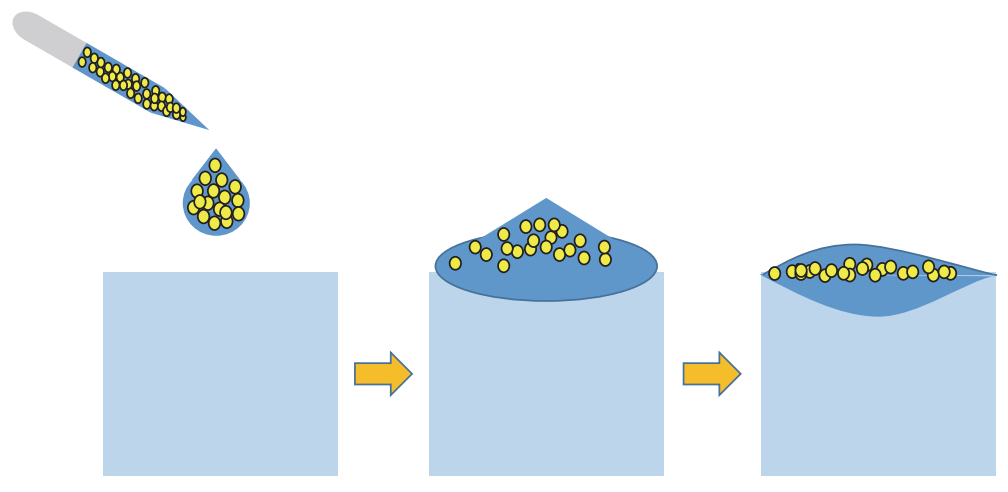

FIGURE 5: Schematic diagram of sandstone soaked in nanoemulsion.

thus nanoemulsions start to get concentrated under surface tension and form a solid thin film on top of the shale rock surfaces. That is the reason why the wettability of the shale rocks was changed [25-28].

\section{Conclusions}

In this work, we designed a new nanoemulsion and proved that the nanoemulsions can greatly improve the wettability of the sandstone surface and form a layer of active agent film on the surface of the rock. The drilling fluid used in the oil field had good ability to curb the anticollapse and lubricate and protect the oil and gas. AFM and FTIR results represent a thin layer of film formed on the surface of the shale rock. Those findings may guide the scientists and engineers regarding designing nanoemulsions with good wettability and stability properties.

\section{Conflicts of Interest}

The authors declare that there are no conflicts of interest regarding the publication of this paper.

\section{Acknowledgments}

The authors thank the National Science Foundation (no. 51505501), Beijing Nova Program (no. Z171100001117058), Tribology Science Fund of State Key Laboratory of Tribology (no. SKLTKF16A06), and Science Foundation of China University of Petroleum (Beijing) (nos. C201603, 2462014YJRC011) for the support.

\section{References}

[1] T. Tadros, "Application of rheology for assessment and prediction of the long-term physical stability of emulsions," Advances in Colloid and Interface Science, vol. 108-109, pp. 227-258, 2004.

[2] K. Meleson, S. Graves, and T. G. Mason, "Formation of concentrated nanoemulsions by extreme shear," Soft Materials, vol. 2, no. 2-3, pp. 109-123, 2004.

[3] N. Sadurní, C. Solans, N. Azemar, and M. J. García-Celma, "Studies on the formation of $\mathrm{O} / \mathrm{W}$ nano-emulsions, by lowenergy emulsification methods, suitable for pharmaceutical applications," European Journal of Pharmaceutical Sciences, vol. 26, no. 5, pp. 438-445, 2005.

[4] P. Fernandez, V. André, J. Rieger, and A. Kühnle, "Nanoemulsion formation by emulsion phase inversion," Colloids and Surfaces A: Physicochemical and Engineering Aspects, vol. 251, no. 1-3, pp. 53-58, 2004.

[5] P. Heunemann, S. Prévost, I. Grillo, C. M. Marino, J. Meyer, and M. Gradzielski, "Formation and structure of slightly anionically charged nanoemulsions obtained by the phase inversion concentration (PIC) method," Soft Matter, vol. 7, no. 12, pp. 56975710, 2011.

[6] D. Morales, J. M. Gutiérrez, M. J. García-Celma, and Y. C. Solans, "A study of the relation between bicontinuous microemulsions and oil/water nano-emulsion formation," Langmuir, vol. 19, no. 18, pp. 7196-7200, 2003.

[7] A. Forgiarini, J. Esquena, C. González, and C. Solans, "Formation of nano-emulsions by low-energy emulsification methods at constant temperature," Langmuir, vol. 17, no. 7, pp. 2076-2083, 2001.

[8] O. Sonneville-Aubrun, J.-T. Simonnet, and F. L'Alloret, "Nanoemulsions: a new vehicle for skincare products," Advances in Colloid and Interface Science, vol. 108-109, pp. 145-149, 2004.

[9] S. M. Jafari, Y. He, and B. Bhandari, "Optimization of nanoemulsions production by microfluidization," European Food Research and Technology, vol. 225, no. 5-6, pp. 733-741, 2007.

[10] D. Guzey and D. J. McClements, "Formation, stability and properties of multilayer emulsions for application in the food industry," Advances in Colloid and Interface Science, vol. 128-130, pp. 227-248, 2006.

[11] C. Solans, P. Izquierdo, and J. Nolla, "Nano-emulsions," Current Opinion in Colloid \& Interface Science, vol. 10, no. 3, pp. 102-110, 2005.

[12] V. G. Babak and M.-J. Stebe, "Highly concentrated emulsions: physicochemical principles of formulation," Journal of Dispersion Science and Technology, vol. 23, no. 1-3, pp. 1-22, 2002.

[13] H. Karbstein and H. Schubert, "Developments in the continuous mechanical production of oil-in-water macro-emulsions," Chemical Engineering and Processing: Process Intensification, vol. 34, no. 3, pp. 205-211, 1995.

[14] Q. Xu, M. Li, L. Zhang, J. Niu, and Z. Xia, "Dynamic adhesion forces between microparticles and substrates in water," Langmuir, vol. 30, no. 37, pp. 11103-11109, 2014. 
[15] Q. Xu, M. Li, J. Niu, and Z. Xia, "Dynamic enhancement in adhesion forces of microparticles on substrates," Langmuir, vol. 29, no. 45, pp. 13743-13749, 2013.

[16] M. Kahlweit, G. Busse, B. Faulhaber, and J. Jen, "Shape changes of globules in nonionic microemulsions," The Journal of Physical Chemistry C, vol. 100, no. 36, pp. 14991-14994, 1996.

[17] S. Engelskirchen, N. Elsner, T. Sottmann, and R. Strey, "Triacylglycerol microemulsions stabilized by alkyl ethoxylate surfactants-a basic study. Phase behavior, interfacial tension and microstructure," Journal of Colloid and Interface Science, vol. 312, no. 1, pp. 114-121, 2007.

[18] K. Aramaki, K. Ozawa, and H. Kunieda, "Effect of temperature on the phase behavior of ionic-nonionic microemulsions," Journal of Colloid and Interface Science, vol. 196, no. 1, pp. 74-78, 1997.

[19] M. A. Pes, K. Aramaki, N. Nakamura, and H. Kunieda, "Temperature-insensitive microemulsions in a sucrose monoalkanoate system," Journal of Colloid and Interface Science, vol. 178, no. 2, pp. 666-672, 1996.

[20] A. C. Lam and R. S. Schechter, "A study of diffusion and electrical conduction in microemulsions," Journal of Colloid and Interface Science, vol. 120, no. 1, pp. 42-55, 1987.

[21] H. Schott, A. E. Royce, and S. K. Han, "Effect of inorganic additives on solutions of nonionic surfactants (VII): cloud point shift values of individual ions," Journal of Colloid and Interface Science, vol. 98, no. 1, pp. 196-201, 1984.

[22] A. Maestro, I. Sole, C. Gonzalez, C. Solans, and J. M. Gutierre, "Influence of the phase behavior on the properties of ionic nanoemulsions prepared by the phase inversion composition method," Colloid Interface Science, vol. 327, no. 2, pp. 433-439, 2008.

[23] Q. Li, Y. Luo, B. Hou, and Z. Han, "Synthesis and mechanism of flocculating-decolorizing agent PAD used for polymersulphonated drilling wastewater," Journal of Residuals Science and Technology, vol. 13, no. 2, pp. 135-143, 2016.

[24] B. Hou, Q. Li, and Y. Luo, "Synthesis and mechanism of a novel organosilicone used as a selective plugging agent," Journal of Residuals Science and Technology, vol. 12, no. 3, pp. 149-156, 2015.

[25] K. S. Sharma, S. R. Patil, and A. K. Rakshit, "Study of the cloud point of C12En nonionic surfactants: effect of additives," Colloids and Surfaces A: Physicochemical and Engineering Aspects, vol. 219, no. 1-3, pp. 67-74, 2003.

[26] T. Gu, S. Qin, and C. Ma, "The effect of electrolytes on the cloud point of mixed solutions of ionic and nonionic surfactants," Journal of Colloid and Interface Science, vol. 127, no. 2, pp. 586$588,1989$.

[27] C. Zhang, H. Wu, and M. R. K. Kessler, "High bio-content polyurethane composites with urethane modified lignin as filler," Polymer, vol. 69, no. 1, pp. 52-57, 2015.

[28] C. Zhang, Y. Xia, R. Chen, S. Huh, P. A. Johnston, and M. R. Kessler, "Soy-castor oil based polyols prepared using a solventfree and catalyst-free method and polyurethanes therefrom," Green Chemistry, vol. 15, no. 6, pp. 1477-1484, 2013. 

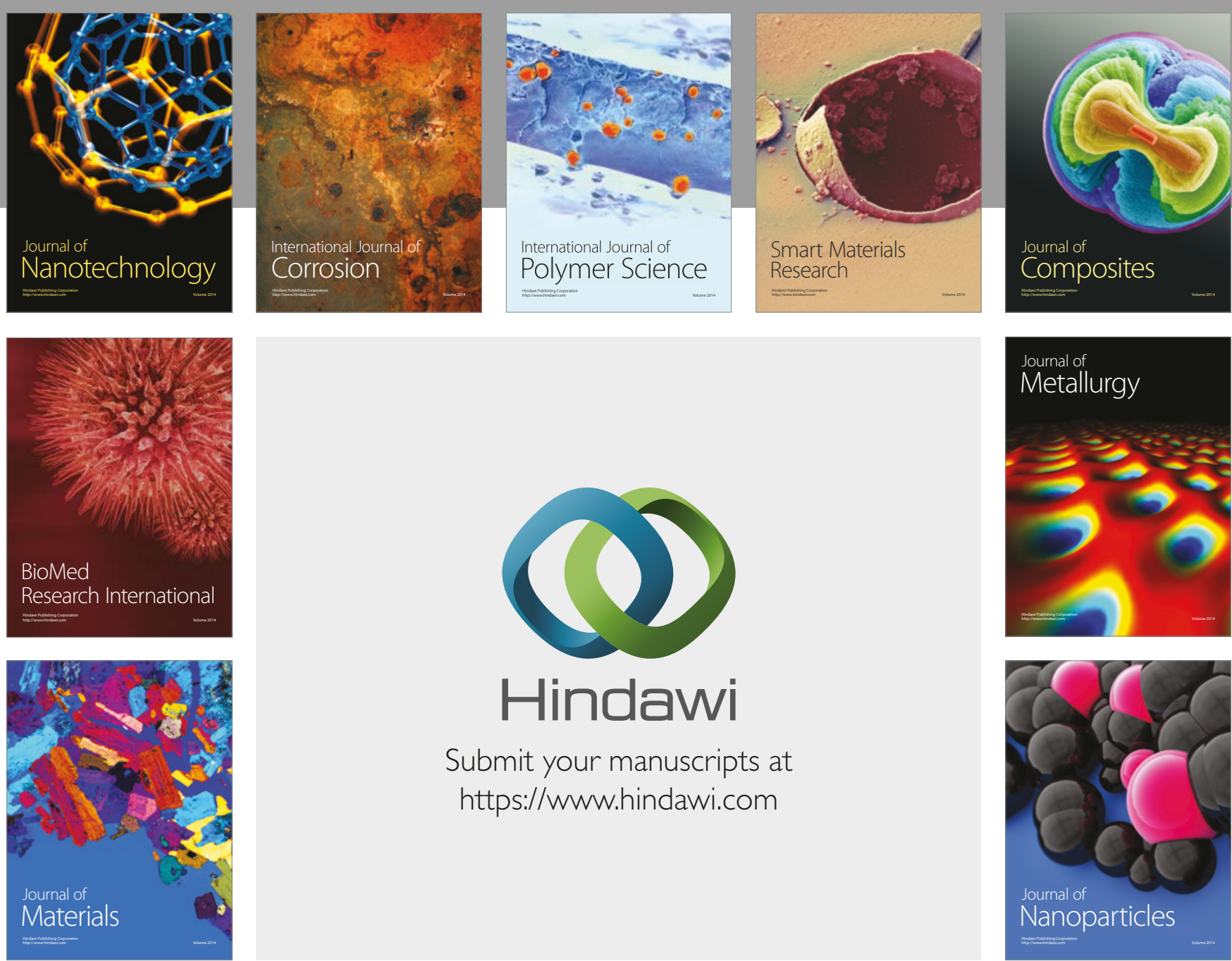

\section{Hindawi}

Submit your manuscripts at

https://www.hindawi.com
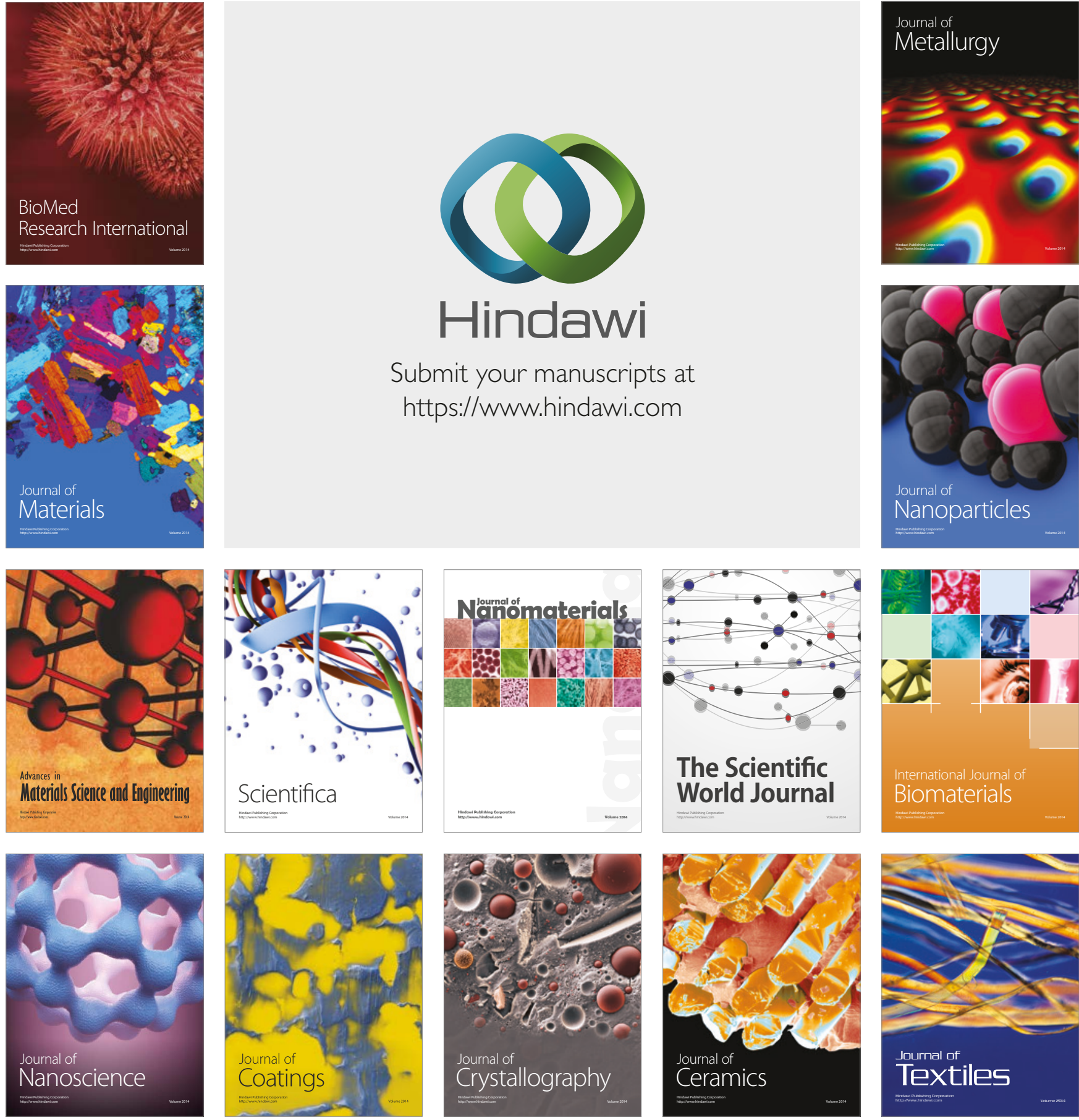

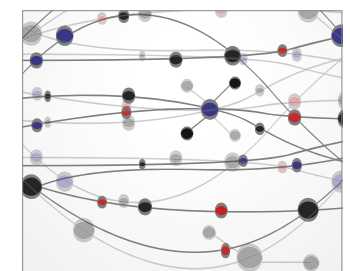

The Scientific World Journal
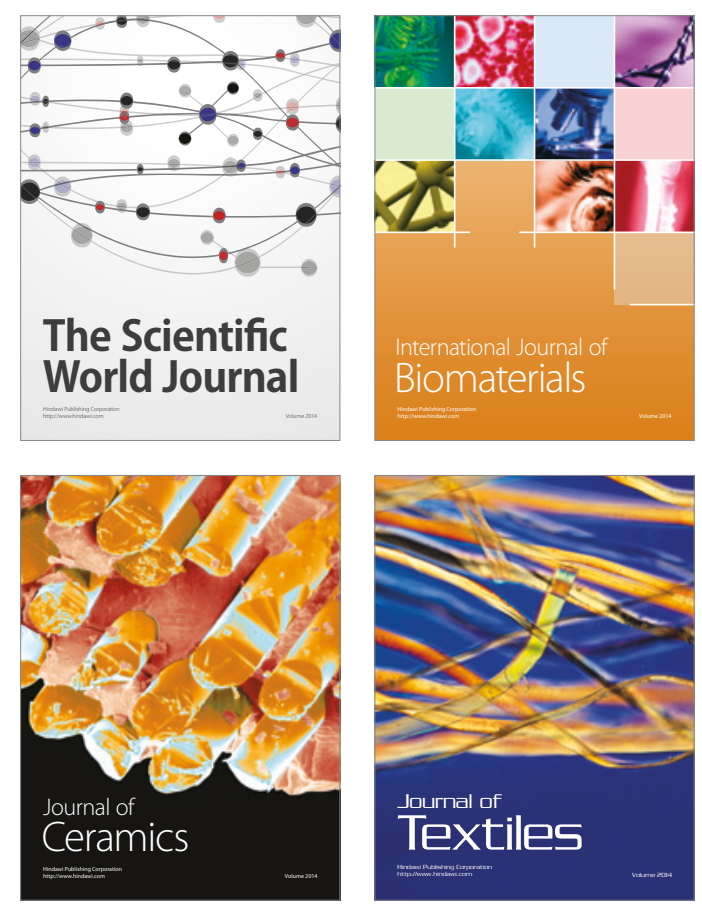